\title{
DUS(Soil)—A Framework for Developing a Minimum Data Set of Soil Health Indicators and Management Guidelines for Farmers
}

\author{
P. M. Govindakrishnan ${ }^{1}$, A. N. Ganeshamurthy ${ }^{2}$, N. K. Krishna Kumar ${ }^{1}$, F. Beggi ${ }^{1}$, S. Bhaskar ${ }^{3}$ \& J. C. Rana ${ }^{1}$ \\ ${ }^{1}$ The Alliance of Bioversity International and International Center for Tropical Agriculture (CIAT), India \\ ${ }^{2}$ Indian Institute of Horticultural Research, Bengaluru, India \\ ${ }^{3}$ Indian Council of Agricultural Research, New Delhi, India \\ Correspondence: P. M. Govindakrishnan, The Alliance of Bioversity International and International Center for \\ Tropical Agriculture (CIAT), India. E-mail: govindakrishnan_pm@yahoo.com
}

Received: September 22, 2021

Accepted: November 24, $2021 \quad$ Online Published: December 15, 2021

doi:10.5539/jas.v14n1p41

URL: https://doi.org/10.5539/jas.v14n1p41

\begin{abstract}
Soil health information is still not widely used in decision making in agriculture. One of the reasons is the lack of a simple and effective method for selection of soil health indicators that have direct relevance to management decisions. A framework for soil health indicators selection and developing location-specific management practices that improve soil health are presented. The framework involves selection of a minimum data set of soil health indicators based on 'DUS(Soil)' criteria. In this framework 'D' represents Distinctness (indicators representing distinct functional soil processes), ' $U$ ' represents Utility (amenability for amelioration of the status of the indicator or altering its impact through management practices) and ' $\mathrm{S}$ ' represents Simplicity (amenability for measurement in the field/small laboratories using simple protocols). This study also outlines a method for developing management guidelines for farmers based on the status of the selected soil health indicators. This involved classifying the status of each of the indicators into three classes. Thereafter, taking cognizance of the agroecological context, suitable field management schedules were developed for each class of the indicators, based on literature and local expert knowledge. The use of this framework was demonstrated by developing management guidelines for a coarse textured soil with optimum $\mathrm{pH}$, low soil carbon, poor in water stable aggregates (highly slaking), optimum porosity and poor in soil macro fauna in Mandla district, Madhya Pradesh, India. The study showed that the framework is flexible, generic as well as simple and is useful to develop site-specific management guidelines logically, to overcome the soil quality constraints.
\end{abstract}

Keywords: DUS(Soil), soil health indicators, soil quality, agricultural soils

\section{Introduction}

Soil quality has been recognized as the foundation of sustainable agriculture. Soil degradation has been reported to be one of the main factors impacting crop yields, resulting in stagnating productivity (Bindraban et al., 2012). The deterioration of soil quality is a problem worldwide (Karlen \& Rice, 2015) and more so in India (Bhattacharyya et al., 2015) because of the adoption of agricultural practices with focused emphasis on high productivity.

The impact of soil health is multidimensional. McBratney, Field, and Koch (2014) reported that soil has an important role in food, water and energy security, climate stability, biodiversity and ecosystem services, hence, soil is as equally important as these issues. Similarly, Keesstra et al. (2016) reported close linkage between soil functions and the Sustainable Development Goals especially goals under serial number 2, 3, 6, 7, 12-15. They have further discussed extensively the various issues arising due to the linkages.

Soil physical, chemical and biological properties are integral components of soil health and studies have been conducted to assess and index soil quality, considering the multiple soil functions (Karlen, Ditzler \& Andrews, 2003; Moebius-Clune et al., 2017). However, the choice of indicators vary widely and many studies have reported different indicators to measure soil health and also criteria for scoring them (Andrews, Karlen, \& Cambardella, 2004; Ganeshamurthy \& Srinivasarao, 2009; Bünemann et al., 2018). The indicators of soil health have been identified by various methods ranging from simple expert opinion to statistical techniques such as Principal Component Analysis (Ghaemi, Astaraei, Emami, Mahalati, \& Sanaeinejad, 2014). 
However, the adoption of soil health evaluation practices by farmers has not been encouraging. One of the reasons could be that there is no general agreement on the best method to use to identify a set of soil health indicators suitable to a particular scenario or circumstance. Further, the results of soil health assessment per se were also observed to be not very encouraging (Roper, Osmond, Heitman, Wagger, \& Reberg-Horton, 2017). They reported no significant correlation between soil health tests and crop yields, suggesting that soil tests should be calibrated to better differentiate soil management effects according to the intrinsic soil limitations. Almost similar observation for translating science into practice by identifying indicators that are useful to land managers had been made by Doran as early as in 2002 (Doran, 2002).

Therefore, this study proposes a simple framework for the selection of minimum data set of soil health indicators and for developing location-specific management practices based on the status of each of the selected indicators.

\section{Materials and Methods}

\subsection{Selection of Indicators}

For the selection of minimum data set of soil health indicators, a set of criteria akin to UPOV's Distinctness, Uniformity and Stability (DUS) criteria (UPOV, 2002), used to distinguish plant varieties was adopted. This was termed 'DUS(Soil)' wherein 'D' represents 'Distinctness' (indicators representing distinct functional soil processes), 'U' represents 'Utility' (amenability for amelioration of the status of the indicator or altering its impact through management practices) and ' $S$ ' represents 'Simplicity' (amenability for measurement in the field/small laboratories using simple protocols). This was accomplished by evaluating the indicators used in various soil health assessment studies reported in literature (Syers, Hamblin, \& Pushparajah, 1995; Kinyangi, 2007; Karlen, Andrews, Wienhold, \& Zobeck, 2008; Schindelbeck et al., 2008; Cardoso et al., 2012) for meeting the three DUS(Soil) criteria viz. Distinctness, Utility and Simplicity. Each of the indicators meeting the three DUS(Soil) criteria were further categorized into three classes based on practical utility for planning of strategic management options. The threshold limits for the different classes were fixed based on literature and expert knowledge.

\subsection{Formulating Management Recommendations Using the Selected Indicators}

To demonstrate the utility of the indicator set for developing location-specific management practices, information on the biophysical context viz. temperature profile, rainfall distribution, soil depth and physiography were collected from literature (Velayutham, D. Mandal, C. Mandal, \& Sehgal, 1999) for Mandla district (80.38 E, $22.6 \mathrm{~N}$ ) in Madhya Pradesh, India. Taking cognizance of the biophysical context, management guidelines for each class of each indicator was developed based on literature and expert consultations. Recommendations for different combinations of classes of the indicators were then derived by synthesis.

\section{Results and Discussion}

\subsection{Selection of Indicators}

The DUS(Soil) criteria envisages the selection of soil health indicators meeting the three criteria, namely Distinctness, Utility and Simplicity. The indicators thus selected are provided in Table 1 and the justification for their selection is provided below.

Table 1. Selected indicators and their threshold values for different classes

\begin{tabular}{|c|c|c|c|c|}
\hline Sl. No. & Indicator & & Classes & Reference/Remarks \\
\hline \multirow[b]{2}{*}{1} & \multirow[b]{2}{*}{ Soil texture } & Coarse & Medium & \multirow[b]{2}{*}{$\begin{array}{l}\text { Adapted from } \\
\text { Ritchey et al. (2015) }\end{array}$} \\
\hline & & Sand, loamy sand & $\begin{array}{l}\text { Sandy loam, sandy clay loam, } \\
\text { loam, clay loam, silt loam, } \\
\text { silty clay loam, silt }\end{array}$ & \\
\hline \multirow{2}{*}{2} & \multirow{2}{*}{ Soil pH } & Low & Optimum & \multirow{2}{*}{ Anonymous (2010) } \\
\hline & & $<6.5$ & $6.5-7.5$ & \\
\hline \multirow{2}{*}{3} & \multirow{2}{*}{ Soil carbon $(\%)$} & Low & Medium & \multirow{2}{*}{ - Anonymous (2011) } \\
\hline & & $<0.5$ & $0.5-0.75$ & \\
\hline 4 & Water stable aggregates & High slaking & Moderate slaking & Adapted from Emerson (1967) \\
\hline \multirow{2}{*}{5} & \multirow{2}{*}{ Soil porosity } & Low & Optimum & \multirow{2}{*}{$\begin{array}{l}\text { Adapted from Pagliai } \\
\text { and Vignozzi (2006) }\end{array}$} \\
\hline & & $<10 \%$ total porosity & $10-25 \%$ total porosity & \\
\hline \multirow[b]{2}{*}{6} & \multirow[b]{2}{*}{$\begin{array}{l}\text { Soil macro } \\
\text { fauna abundance }\end{array}$} & Poor & Moderate & \multirow[b]{2}{*}{$\begin{array}{l}\text { - Adapted from Ganeshamurthy } \\
\text { and Srinivasarao (2009) } \\
\text { and Islam et al. (2017) }\end{array}$} \\
\hline & & $\begin{array}{l}0 \text { to }<3 \text { earth worms } \\
\text { or macro life per spade } \\
\text { full of surface soil) }\end{array}$ & $\begin{array}{l}3 \text { to } 6 \text { earth worms or } \\
\text { macro life per spade } \\
\text { full of surface soil) }\end{array}$ & \\
\hline
\end{tabular}




\subsubsection{Distinctness}

Soil texture is the major determinant of the physical dynamics of soil water (Scott, Cole, Elliott, \& Huffman, 1996; Fernandez-Illescas, Porporato, Laio, \& Rodriguez-Iturbe, 2001) and this is one of its unique features. It is also an important factor determining the soil's erosion potential. Due to these distinct characteristics, soil texture was chosen as an indicator of soil health. The three distinct classes of texture identified were coarse, medium and fine texture soils (Table 1).

The second indicator meeting the 'Distinctness' criteria is the soil $\mathrm{pH}$. Soil $\mathrm{pH}$ plays a unique role in soil health primarily in terms of determining availability of nutrients in view of its major role in affecting the chemical dynamics of soil nutrients. It also determines the soil biological diversity to some extent (Anonymous, 2010; Neina, 2019). Soil pH is also a determinant of soil structure especially at the extreme values. Information on these characteristics are important for developing appropriate management schedules and hence soil $\mathrm{pH}$ meets the distinctness criteria. This indicator was also categorized into three groups viz. low, optimum and high in view of the requirement of such information for strategic decisions like choice of crops, fertilizer type, designing cultivation practices, use of amendments etc.

Soil carbon influences many physical, chemical and biological properties of soil (Reeves, 1997; Murphy, 2015). One of its unique roles is as an integrator of many soil functional processes (Lorenz \& Lal, 2016) and this perhaps is its most distinguishing characteristic. Due to this distinct feature, soil organic carbon (OC) was also identified as an important soil health indicator. The three classes of soil carbon, viz. low, medium and high, were fixed as per the classification used by the soil testing laboratories in India (Anonymous, 2011).

Water stable aggregates (WSAs), is an important indicator of the soil structure and thus the effective soil porosity, hence it was selected as the fourth indicator. Through its effect on soil structure, WSAs have strong interaction with the soil organic matter and thus on soil aeration, soil micro flora and crop growth (Albrecht, Angers, Beare, \& Blanchart, 1998). WSAs were categorized into three classes viz. high dispersion, moderate dispersion and no dispersion types, based on ability to withstand the disruptive force of water (Table 1).

Soil porosity per se is the fifth soil health indicator selected as per the 'Distinctness' criteria because of its distinct characteristic as a quantitative indicator of the ratio of non-solid volume to the total volume and thus is a simple indicator of soil compactness. Soil porosity greatly influences root penetration and growth, water movement as well as many soil chemical and biological properties (Pagliai \& Vignozzi, 2006).

Soil fauna is intricately linked to many ecosystem functions. Lavelle (1996), Kumar and Singh (2016), Briones (2018), and Sofo, Mininni, and Ricciuti (2020) have discussed the diverse functions of soil fauna. From their work it is apparent that the soil faunal communities are responsible for performing many activities according to which they have been classified as decomposers, shredders, predators, herbivores, fungal feeders and burrowers. The soil fauna also stimulate the growth and activities of microorganisms in the soil including bacteria, fungi, protozoa etc. Apart from this, soil fauna mix and aggregate soil, increase infiltration, improve water holding capacity, provide channels for root growth, shred and bury plant residue and all these favour microbial activity. Decrease in the abundance and diversity soil fauna would result in shifts in community structure and may also affect the resilience of soil ecosystems. Therefore, any shift or disturbance in soil fauna will negatively impact the ecosystem services. Hence, the soil macro fauna population was selected as the sixth indicator as a proxy of soil biological health. Both porosity and soil macro fauna were also categorized into three classes (Table 1) based on their utility for strategic decisions.

\subsubsection{Utility}

Among the six indicators meeting the 'Distinctness' criterion, soil texture and soil $\mathrm{pH}$ are the two indicators that represent the inherent soil quality. While amelioration of their status per se is quite difficult, their impact can be altered by the choice of appropriate management practices like type of tillage practices, dose and method of application of nutrients, irrigation management techniques etc, in the case of soil texture. For example different tillage practices have to be adopted for different textural soils for proper seedbed preparation and also ensuring soil conservation. Similarly adopting frequent light irrigation can mitigate the high water percolation losses in coarse textured soils. Split application of nutrients is another agro-technique to reduce leaching losses in such soils. Similarly, for the other soil textural classes different agro-techniques can be adopted to mitigate their negative impact to a great extent.

The importance of soil $\mathrm{pH}$ and the various functions it governs have been studied extensively and have also been reviewed (Anonymous, 2010; Miller, 2016; Neina, 2019). Briefly, it controls the solubility, mobility, and availability of nutrients. The availability of $\mathrm{P}, \mathrm{K}, \mathrm{Ca}$ and $\mathrm{Mg}$ are less in acidic soils due to fixation or leaching 
out. Aluminium toxicity can also be an issue in acidic soils while in alkaline soils, volatilization losses of $\mathrm{N}$ can be an issue. Soil $\mathrm{pH}$ also influences the microbial population as a consequence of which mineralization in soils is affected. Thus, soil $\mathrm{pH}$ influences the availability and uptake of nutrients, hence macro and micronutrient management schedules and application soil amendment practices have to be adapted to its status. For instance, in soils that have slightly lower or higher $\mathrm{pH}$ than the optimum range, management through crop selection and selection of appropriate type of fertilizers to apply may suffice. However, for soils with $\mathrm{pH}$ values of $<5.5$ or $>$ 8.0 , use of amendments also would be necessary. Thus, both soil texture and $\mathrm{pH}$ meet the utility criteria since their influence can be modified through management practices.

The other four indicators, namely, soil carbon, water stable aggregates, soil porosity and soil biota represent the dynamic soil qualities, hence, their status can be more easily altered through management practices. Soil carbon status can be improved by a variety of management practices like green manuring, addition of farmyard manure (FYM), residue management, zero tillage etc. while the status of WSAs can be improved through minimum tillage practices, as well as through the introduction of certain crops that promote soil aggregation, like ley farming and introduction of legumes in cropping systems, as well as by liming. In the case of soil porosity, its status can be improved primarily through appropriate tillage practices, while the status of soil biota are amenable for alteration through the addition of organic manures and products rich in microbial population like jeevamrit, as well as by ensuring low pollutant load in the soil. Thus, these four indicators also meet the utility criteria.

\subsubsection{Simplicity}

As regards the third DUS(Soil) criteria, i.e., 'Simplicity', simple protocols for field assessment of all six indicators are available. Perusal of published literature shows that: (i) soil texture can be easily measured using the 'Feel' method (Ritchey, McGrath, \& Gehring, 2015), (ii) soil pH can be measured using litmus paper (Warburton-Brown \& Kemeny, 2015), (iii) soil carbon can be measured through a simple field method (Bowman, 1994), (iv) WSAs can be measured using the slaking test (Emerson, 1967), (v) soil porosity can be measured by the amount of water required for bringing the soil to saturation using a measuring cylinder (Anonymous, 2018) and (vi) soil macro fauna population can be estimated by visual observations and then rating it (Islam, Bhuiyan, Mohinuzzaman, Ali, \& Moon, 2017). Thus, all the six indicators selected can be easily measured in the field/small laboratories and hence meet the simplicity criteria.

\subsection{Formulating Management Recommendations Using the Selected Indicators}

Management recommendations are formulated considering the contextual information on biophysical aspects of the region together with the status of the soil health indicators. The information on the biophysical aspects collected from the literature for Mandla are presented below.

\subsubsection{Biophysical Context}

The temperature profile and rainfall distribution of Mandla district extracted from New_LocClim (Grieser, Gommes, \& Bernardi, 2006) are provided in Table 2. Perusal of the table shows that the yearly mean maximum temperature at Mandla is $31.7^{\circ} \mathrm{C}$ while the yearly mean minimum temperature is $17.1{ }^{\circ} \mathrm{C}$. The mean maximum temperature peak touches $41.2{ }^{\circ} \mathrm{C}$ during May. As regards rainfall, Mandla receives a total annual rainfall of $1420 \mathrm{~mm}$ but more than $88 \%$ of that $(1257 \mathrm{~mm})$ is received in four months, from June to September. Thus, the rainfall is highly seasonal and pre-monsoon and post-monsoon showers are negligible.

The agro-ecological characteristics of the district have been described in detail (Velayutham et al., 1999). Briefly, it is characterized as hot, sub humid climate with red and black soils. The dry period occurs from February to May suggesting typic ustic soil moisture regime and the post-rainy period remains fairly dry. The mean annual soil temperature of more than $22{ }^{\circ} \mathrm{C}$ qualifies the area to be hyperthermic soil temperature regime. Mixed red and black soils are the common soil types in the district. The gently sloping uplands in Mandla are of mixed red and black type soils with shallow depth. In the valleys, the soils are largely medium and deep black soils having high swell-shrink potential and are interspersed with patches of red soils on ridges (Orr, 2008; Nahatkar, Pahalwan, Vani, Sharma, Rathi, \& Khare, 2021). The Length of the Growing Period ranges from 150-180 d. The main constraints due to the climatic, edaphic and physiographic features include difficulty in tillage operations due to poor temporal distribution of rainfall, narrow workable moisture conditions in the heavy, highly cracking clay soils in the lowlands and poor soil depth in the case of red soils in the uplands. Uncertainty in the onset of the rainy season, as well as the risk of drought due to prolonged dry spells, are also important constraints in the area. Another constraint is the risk of inundation of the cropped areas during the rainy season due to poor temporal distribution of rainfall and low infiltration rate in the heavy clay soils in the lowlands. Significant soil erosion especially in the uplands is another consequence of the edaphic, physiographic and rainfall distribution pattern in the region. 
Table 2. Meteorological data of Mandla district (monthly means)

\begin{tabular}{lllll}
\hline Month & Maximum Temperature $\left({ }^{\mathbf{0}} \mathbf{C}\right)$ & Minimum Temperature $\left({ }^{\mathbf{0}} \mathbf{C}\right)$ & Rainfall $(\mathbf{m m})$ & Sunshine hours (Fraction \%) \\
\hline January & 26 & 8.8 & 25 & 71 \\
February & 29.2 & 10.1 & 16 & 74 \\
March & 33.7 & 14.1 & 35 & 74 \\
April & 37.9 & 19.1 & 12 & 71 \\
May & 41.2 & 24.2 & 8 & 71 \\
June & 37.5 & 25.2 & 151 & 49 \\
July & 30.1 & 23.2 & 456 & 24 \\
August & 29.2 & 23.1 & 433 & 25 \\
September & 30.2 & 22.2 & 217 & 46 \\
October & 30.5 & 17.6 & 45 & 69 \\
November & 28.1 & 9.8 & 1 & 77 \\
December & 26.6 & 7.8 & 21 & 76 \\
Year & 31.7 & 17.1 & $1420^{*}$ & 60.58 \\
\hline
\end{tabular}

Note. ${ }^{*}$ Total rainfall.

\subsubsection{Tailoring Management Practices According to Soil Health Status}

The recommendations that emerge considering the contextual information and the status of all six indicators viz. coarse texture, optimum $\mathrm{pH}$, low soil carbon, poor WSAs (highly slaking), optimum porosity and poor soil macro fauna are given in Appendix A. Perusal of these recommendations show that they are holistic and practical. The status of each of the six indicators, as well as the biophysical context have been considered while developing the recommendations. e.g., practices for control of both wind and water erosion including a whole set of agro-techniques like adoption of agroforestry, grassed waterways and having small plots with thick bunds have been suggested to control erosion in view of the high rainfall intensity. Similarly, management practices other than green manuring have been suggested to increase soil carbon (Appendix A) because Mandla does not receive sufficient pre-monsoon showers to support a green manure crop before the main cropping season. Besides, the coarse textured gravelly upland soils at Mandla are very shallow and this makes plough down of green manure crops difficult. The rainfall pattern also gets reflected in the recommendation of choice of the crops in the cropping system. Thus, consideration of the status of the indicators together with the biophysical context enables precise location-specific management options to be developed drawing on the expertise of local agricultural specialists and published literature.

The importance of soil health has long been recognized and serious efforts were made towards its assessment and management, however, success in its widespread adoption was limited. Ingram (2008) studied the information needs of farmers for sustainable soil management and found that they lack in-depth scientific knowledge, hence, they may not be able to implement complex practices. Griffiths et al. (2015) called for management decisions that improve soil quality/health to be taken at the individual field scale because they found that the effects of management practices were overridden by the soil properties. Even though serious efforts have been made to assess soil health, success in the widespread adoption of practices to improve soil health has been poor (Carlisle, 2016). According to Brown and Herrick (2016), it is highly challenging to ensure that land use and management are essential components of soil health. This could be due to the fact that studies commonly have provided information on sustainable soil management in a general way (Stockdale, Griffiths, Hargreaves, Bhogal, Crotty, \& Watson, 2018) while the farmers require specific recommendations tailored to his situation.

This study proposes a simple, generic, flexible framework called DUS(Soil) for identifying a minimum data set of soil health indicators. The flexibility of the framework lies in the fact that the selection of indicators and the criteria for fixing the threshold limits of the indicators into different classes can be adapted to the research data relevant to the local situations. The study further shows that formulating management practices that consider the indicators' status together with the biophysical context allows the formulation of location-specific package of practices to overcome the soil quality constraints.

\section{Conclusions}

In this study a framework for a simple and generic method for selection of minimum data set of soil health indicators called DUS(Soil) was developed. Using this framework, six soil health indicators were identified: texture, $\mathrm{pH}$, soil carbon, water stable aggregates, porosity and soil macro fauna. The study has also proposed a method for developing site-specific management practices based on the soil health indicator status, as well as the 
biophysical context. This framework is flexible and is therefore expected to simplify the identification of minimum data set of soil health indicators for any agro-ecoregion. The procedure outlined for developing management schedules considering the biophysical context and the status of the soil health indicators is expected to lead to the development of management schedules relevant to the soil health status and having greater potential for adoption.

\section{Acknowledgements}

This research was conducted with the financial support from the German Federal Ministry for Economic Cooperation and Development (BMZ)/Deutsche Gesellschaft für Internationale Zusammenarbeit (GIZ) under the project number: 16.7860.6-001.00, contract number: 81206856, and the Department of Agricultural Research and Education, Government of India/The Indian Council of Agricultural Research under the ICAR-Bioversity International Annual Work plan. Their support is gratefully acknowledged. The views expressed in this document are of the authors and cannot be taken to reflect the official opinions of the organizations mentioned.

The authors thank Drs DM Hegde (Ex-Director, ICAR-Directorate of Oilseeds Research) and Virendra Pal Singh (The Alliance of Bioversity International and the International Center for Tropical Agriculture (CIAT), India) for their constructive suggestions on the draft manuscript. The authors also thank Drs RD Rai, Ex-Scientist CSIR, Late Dr R. Palaniappan, Retd. Head, Division of Soil Science, Indian Institute of Horticulural Research, Bengaluru, Dr Vadivelu, Retd. Head, National Bureau of Soil Survey and Land Use Planning, Bengaluru, Officers of Krishi Vigyan Kendra, Mandla, Agricultural Technology Management Agency (ATMA), Mandla, Officers of Soil Testing Laboratory, Mandla and staff of Foundation for Ecological Security Mandla for their support in the execution of the project. We also acknowledge Olga Spellman (The Alliance of Bioversity International and CIAT) for technical and English editing of this manuscript.

\section{References}

Albrecht, A., Angers, D. A., Beare, M., \& Blanchart, E. (1998). Soil aggregation, soil organic matter and soil biota interactions: implications for soil fertility recapitalization in the tropics (Scientific Registration No. 212). Retrieved from https://www.researchgate.net/publication/50280665

Andrews, S. S., Karlen, D. L., \& Cambardella, C. A. (2004). The Soil Management Assessment Framework: A Quantitative Soil Quality Evaluation Method. Soil Science Society of America Journal, 68, 1945-1962. https://doi.org/10.2136/sssaj2004.1945

Anonymous. (2010). Soil pH and the availability of plant nutrients. IPNI Plant Nutrition Today (No. 2). Retrieved from http://www.ipni.net/publication/pnt-na.nsf/0/013F96E7280A696985257CD6006FB98F/\$FI LE/PNT-2010-Fall-02.pdf

Anonymous. (2011). Methods Manual. Soil Testing in India. Department of Agriculture and Cooperation, Ministry of Agriculture, Government of India, New Delhi. Retrieved from https://www.scirp.org/ (S(351jmbntvnsjt1aadkposzje))/reference/ReferencesPapers.aspx?ReferenceID=1651999

Anonymous. (2018). How do scientists measure the porosity of soil. Socratic. Retrieved from https://socratic.org/questions/how-do-scientists- measure-the-porosity-of-soil.html

Bhattacharyya, R., Ghosh, B. N., Mishra, P. K., Mandal, B., Rao, C. S., Sarkar, D., ... Franzluebbers, A. J. (2015). Soil Degradation in India: Challenges and Potential Solutions. Sustainability, 7, 3528-3570. https://doi.org/10.3390/su7043528

Bindraban, P. S., van der Velde, M., Ye, L., van den Berg, M., Materechera, S., Kiba, D. I., ... van Lynden, G. (2012). Assessing the impact of soil degradation on food production. Current Opinion in Environmental Sustainability, 4, 478-488. https://doi.org/10.1016/j.cosust.2012.09.015

Bowman, R. A. (1994). Field Methods to Estimate Soil Organic Matter (Conservation Tillage Fact Sheet \#5). USDA-ARS and USDA-NRCS, Akron, CO. Retrieved from https:/www.ars.usda.gov/ARSUserFiles/ 0100000/19901999documents/336\%201997\%20Bowman\%20Conserv\%20Tillage\%20Fact\%20Sht.pdf

Briones, M. J. I. (2018). The Serendipitous Value of Soil Fauna in Ecosystem Functioning: The Unexplained Explained. Frontiers in Environmental Science, 6, Article 149. https://doi.org/10.3389/fenvs.2018.00149

Brown, J. R., \& Herrick, J. E. (2016). Making soil health a part of rangeland management. Journal of Soil and Water Conservation, 71, 55A-60A. https://doi.org/10.2489/jswc.71.3.55A 
Bünemann, E. K., Bongiorno, G., Bai, Z., Creamer, R. E., de Deyn, G., de Goede, R., ... Brussaard, L. (2018). Soil quality-A critical review. Soil Biology and Biochemistry, 120, 105-125. https://oi.org/10.1016/ j.soilbio.2018.01.030

Cardoso, E. J. B. N., Vasconcellos, R. L. F., Bini, D., Miyauchi, M. Y. H., dos Santos, C. A., Alves, P. R. L., ... Nogueira, M. A. (2012). Soil health: looking for suitable indicators. What should be considered to assess the effects of use and management on soil health? Scientia Agricola, 70, 274-289. https://doi.org/ 10.1590/S0103-90162013000400009

Carlisle, L. (2016). Factors Influencing Farmer Adoption of Soil Health Practices in the United States: A Narrative Review. Agroecology and Sustainable Food Systems, 40(6), 583-613. https://doi.org/10.1080/ 21683565.2016.1156596

Doran, J. W. (2002). Soil health and global sustainability: Translating science into practice. Agriculture Ecosystems \& Environment, 88, 119-127. https://doi.org/10.1016/S0167-8809(01)00246-8

Emerson, W. W. (1967). A classification of soil aggregates based on their coherence in water. Australian Journal of Soil Research, 5, 47-57. https://doi.org/10.1071/SR9670047

Fernandez-Illescas, C. P., Porporato, A., Laio, F., \& Rodriguez-Iturbe, I. (2001). The ecohydrological role of soil texture in a water-limited ecosystem. Water Resources Research, 37(12), 2863-2872. https://doi.org/ 10.1029/2000WR000121

Ganeshamurthy, A. N., \& Srinivasarao, C. H. (2009). Assessment of field indicators of soil health following long term cultivation of pulses on Entisols in Indo Gangetic Plain. Journal of the Indian Society of Soil Science, $57,76-80$.

Ghaemi, M., Astaraei, A. R., Emami, H., Mahalati, M. N., \& Sanaeinejad, S. H. (2014). Determining soil indicators for soil sustainability assessment using principal component analysis of Astan Quds-East of Mashhad-Iran. Journal of Soil Science and Plant Nutrition, 14, 987-1004. https://doi.org/10.4067/ S0718-95162014005000077

Grieser, J., Gommes, R., \& Bernardi, M. (2006). New LocClim-The local climate estimator of FAO. Geophysical Research Abstracts, 8, 08305. Retrieved from https:/www.researchgate.net/publication/ 288879070

Griffiths, B. S., Hallett, P. D., Daniell, T. J., Hawes, C., Squire, G. S., Mitchell, S. M., ... Nevison, I. (2015). Probing soil physical and biological resilience data from a broad sampling of arable farms in Scotland. Soil Use and Management, 31, 491-503. https://doi.org/10.1111/sum.12214

Ingram, J. (2008). Are farmers in England equipped to meet the knowledge challenge of sustainable soil management? An analysis of farmer and advisor views. Journal of Environmental Management, 86, 214-228. https://doi.org/10.1016/j.jenvman.2006.12.036

Islam, S. M. D., Bhuiyan, M. A. H., Mohinuzzaman, M., Ali, M. H., \& Moon, S. R. (2017). A Soil Health Card (SHC) for soil quality monitoring of agricultural lands in south-eastern coastal region of Bangladesh. Environmental Systems Research, 6, 15. https://doi.org/10.1186/s40068-017-0092-7

Karlen, D. L. Andrews, S. S., Wienhold, B. J., \& Zobeck, T. M. (2008). Soil Quality Assessment: Past, Present and Future. Journal of Integrative Bioscience, 6, 3-14. Retrieved from https://digitalcommons.unl.edu/ usdaarsfacpub/1203

Karlen, D. L. Ditzler, C. A., \& Andrews, S. S. (2003). Soil quality: Why and how? Geoderma, 114, $145-156$. https://doi.org/10.1016/S0016-7061(03)00039-9

Karlen, D. L., \& Rice, C. W. (2015). Soil Degradation: Will Humankind Ever Learn? Sustainability, 7, 12490-12501. https://doi.org/10.3390/su70912490

Keesstra, S. D., Bouma, J., Wallinga, J., Tittonell, P., Smith, P., Cerdà, A., ... Fresco, L. O. (2016). The significance of soils and soil science towards realization of the United Nations Sustainable Development Goals. Soil, 2, 111-128. https://doi.org/10.5194/soil-2-111-2016

Kinyangi, J. (2007). Soil Health and Soil Quality: A Review. Retrieved from https:/www.researchgate.net/ publication/277296620_SOIL_HEALTH_AND_SOIL_QUALITY_A_REVIEW

Kumar, U., \& Singh, R. (2016). Soil Fauna: A Retrospection with Reference to Indian Soil. International Journal of Research Studies in Zoology, 2, 17-38. https://doi.org/10.20431/2454-941X.0203003 
Lavelle, P. (1996). Diversity of Soil Fauna and Ecosystem Function. Biology International (No. 33). Retrieved from https://citeseerx.ist.psu.edu/viewdoc/download?doi=10.1.1.491.2284\&rep=rep1\&type=pdf

Lorenz, K., \& Lal, R. (2016). Soil Organic Carbon - An Appropriate Indicator to Monitor Trends of Land and Soil Degradation within the SDG Framework? http://www.umweltbundesamt.de/publikationen

McBratney, A., Field, D. J., \& Koch, A. (2014). The dimensions of soil security. Geoderma, 213, 203-213. https://doi.org/10.1016/j.geoderma.2013.08.013

Miller, J. O. (2016). Soil pH Affects Nutrient Availability (Technical Report FS-1054). University of Maryland Extension. Retrieved from https://www.researchgate.net/publication/305775103

Moebius-Clune, B. N., Moebius-Clune, D. J., Gugino, B. K., Idowu, O. J., Schindelbeck, R. R., Ristow, A. J., ... Abawi, G. S. (2017). Comprehensive Assessment of Soil Health-The Cornell Framework (3.2 ed.). Cornell University, Geneva, NY. Retrieved from http://www.css.cornell.edu/extension/soil-health/manual.pdf

Murphy, B. (2015). Key soil functional properties affected by soil organic matter-Evidence from published literature. IOP Conference Series: Earth and Environmental Science, 25, 012008. https://doi.org/10.1088/ $1755-1315 / 25 / 1 / 012008$

Nahatkar, S. B., Pahalwan, D., Vani, G. K., Sharma, H. O., Rathi, D., \& Khare, D. (2021). Agriculture Atlas of the State of Madhya Pradesh (p. 19). Office of the Dean Faculty of Agriculture, JNKVV, Jabalpur. Retrieved from http://jnkvv.org/PDF/27012021221604Atlas\%20JNKVV\%20FINAL.pdf

Neina, D. (2019). The Role of Soil pH in Plant Nutrition and Soil Remediation. Applied and Environmental Soil Science, 2019, Article ID 5794869. https://doi.org/10.1155/2019/5794869

Orr, M. (2008). A Rapid Landscape Assessment on Environmental Vulnerability of the Matiyari Watershed, Mandla District, Madhya Pradesh. Foundation for Ecological Security. Retrieved from http://fes.org.in/ resources/studies-\&-reports/internship-reports/A\%20Rapid\%20Landscape\%20Assessment\%20on\%20Envir onmental.pdf

Pagliai, M., \& Vignozzi, N. (2006). Soil Porosity as an indicator of soil health. Annals of Arid Zone, 45, 259-286.

Reeves, D. W. (1997). The role of soil organic matter in maintaining soil quality in continuous cropping systems. Soil \& Tillage Research, 43, 131-167. https://doi.org/10.1016/S0167-1987(97)00038-X

Ritchey, E. L., McGrath, J. M., \& Gehring, D. (2015). Determining Soil Texture by Feel. Agriculture and Natural Resources Publications, 139. Retrieved from https://uknowledge.uky.edu/cgi/viewcontent.cgi? article $=1139 \&$ context $=$ anr_reports

Roper, W. R., Osmond, D. L., Heitman, J. L., Wagger, M. G., \& Reberg-Horton, S. C. (2017). Soil Health Indicators Do Not Differentiate among Agronomic Management Systems in North Carolina. Soil Science Society of America Journal, 81, 828-843. https://doi.org/10.2136/sssaj2016.12.0400

Schindelbeck, R. R., van Es, H. M., Abawi, G. S., Wolfe, D. W., Whitlow, T. L., Gugino, B. K., .. Moebius, B. N. (2008). Comprehensive assessment of soil quality for landscape and urban management. Landscape and Urban Planning, 88, 73-80. https://doi.org/10.1016/j.landurbplan.2008.08.006

Scott, N. A., Cole, C. V., Elliott, E. T., \& Huffman, S. A. (1996). Soil Textural Control on decomposition and Soil Organic Matter Dynamics. Soil Science Society of America Journal, 60, 1102-1109. https://doi.org/ 10.2136/sssaj1996.03615995006000040020x

Sofo, A., Mininni, A. N., \& Ricciuti, P. (2020). Soil Macrofauna: A key Factor for Increasing Soil Fertility and Promoting Sustainable Soil Use in Fruit Orchard Agrosystems. Agronomy, 10, 456. https://doi.org/ 10.3390/agronomy10040456

Stockdale, E. A., Griffiths, B. S., Hargreaves, P. R., Bhogal, A., Crotty, F. V., \& Watson, C. A. (2018). Conceptual framework underpinning management of soil health-supporting site-specific delivery of sustainable agroecosystems. Food Energy Security, 2018, e00158. https://doi.org/10.1002/fes3.158

Syers, J. K., Hamblin, A., \& Pushparajah, E. (1995). Indicators and thresholds for the evaluation of sustainable land management. Canadian Journal of Soil Science, 75, 423-428. https://doi.org/10.4141/cjss95-062

UPOV. (2002). General introduction to the examination of distinctness, uniformity and stability and the development of harmonized descriptons of new varieties of plants (Document TG/I/3). UPOV, Geneva, Switzerland. Retrieved from https://www.upov.int/tgp/en/ introduction_dus.html 
Velayutham, M., Mandal, D. K., Mandal, C., \& Sehgal, J. (1999). AgroEcological Subregions of India for Planning and Development (NBSS\&LUP Publ. No. 35). National Bureau of Soil Survey and Land Use Planning, Nagpur.

Warburton-Brown, C., \& Kemeny, T. (2015). Permaculture Research: Soil Test Handbook (Version 2.1, p. 14). The Permaculture Association, Hollybush Conservation Centre, Broad Lane, Kirkstall, Leeds. Retrieved from https://www.permaculture.org.uk/sites/default/files/page/document/permaculture_research_soil_test_ hb_v.2.1_0.pdf

\section{Appendix A}

Recommendations of management practices for soils of coarse texture, optimum pH, low soil carbon, poor WSA (highly slaking), optimum porosity and poor soil macro fauna at Mandla

Wind and water erosion can be a serious problem in coarse textured soils especially in slopes. Agroforestry practices should be adopted by growing fruit trees like tamarind, drumstick trees in the bunds surrounding the fields. The plot size may be kept small and row direction of the crops should be across the slope. Proper management of water lines with grassed water ways may be adopted to reduce water erosion.

As regards fertilization, preference may be given for slow release fertilizer application or split application of nutrients especially nitrogen.

Compaction is generally not a serious issue in these soils in the region, but surface crusting may be a problem in low organic matter and light textured soils. A light harrowing might help, or rotary hoes can be effective tools for fracturing crusted soils and allowing seedlings to emerge. When using a rotary hoe, the soil should be moist to dry. Application of $2.5 \mathrm{t} / \mathrm{ha}$ of phospho-gypsum on the soil surface to decrease surface crusting may also be adopted. Tank silt application $(10 \mathrm{t} / \mathrm{ha}) /$ well decomposed manure $(5 \mathrm{t} / \mathrm{ha})$ or leaf litter application may also be considered if the soil texture is too coarse. All amendments must be applied during pre-monsoon period and must be mixed well with the soil after application.

In neutral soils, all forms of fertilizers can be used without risk. However, if the fields are on the slopes, then incorporation of fertilizers into soil or deep placement is recommended rather than broadcasting to avoid loss through surface runoff.

To improve water stable aggregates status, adoption of minimum tillage/zero tillage practices would be beneficial. Silvi-pastoral practices may also be adopted to introduce grasses in rotation. Preference may be given for local grasses like lemon grass, crops like kodo and kutki and legumes like horse gram, cowpeas, soybean and lentils for inclusion in rotation. Inoculation of soil with Microbial products like Jeevamrit both direct field application and in the nursery of transplanted crops may be adopted in the kharif season. Vermicomposts and vermiwash may be applied as frequently as possible.

Due to low organic carbon status and poor soil depth, tree lopping from trees grown along the hedges by adoption of agroforestry practices would provide necessary organic matter in these soils. Application of 10 to $25 \mathrm{t} / \mathrm{ha}$ of any available organic manures like FYM/well decomposed manure/leaf litter/biochar/tree loppings at the beginning of monsoon season is also recommended.

For improving the soil fauna status, it is recommended to leave the stubble of winter crops on the soil surface to act as stubble mulch to reduce soil temperature and avoid soil disturbance during summer months. At the onset of rains, recycle the residues by inoculation with biofertilizers containing $\mathrm{N}$ fixers and phosphorus solubilizing microorganisms. Though pollutants may not be a determinant of low soil biota status in Mandla soils in view of the low levels of agrochemical inputs, the pesticides usage may however be closely monitored. The above practices would encourage buildup of soil organic carbon and in turn encourage buildup of the soil biota population.

\section{Copyrights}

Copyright for this article is retained by the author(s), with first publication rights granted to the journal.

This is an open-access article distributed under the terms and conditions of the Creative Commons Attribution license (http://creativecommons.org/licenses/by/4.0/). 